\title{
Applying a Risk-Adjustment Framework to Primary Care: Can We Improve on Existing Measures?
}

\author{
Amy K. Rosen, $P b D^{1}$ \\ Robert Reid, $M D, P b D^{2,3}$ \\ Anne-Marie Broemeling, $\mathrm{PbD}^{2}$ \\ Carter C. Rakovski, MA, MS ${ }^{4}$ \\ ${ }^{1}$ Center for Health Quality, Outcomes and \\ Economic Research, Bedford, Mass $;$ Boston \\ University School of Public Health, \\ Department of Health Services, Boston, \\ Mass \\ ${ }^{2}$ Center for Health Services and Policy \\ Research, University of British Columbia, \\ Vancouver, British Columbia \\ ${ }^{3}$ Department of Health Care and Epidemi- \\ ology, University of British Columbia, Van- \\ couver, British Columbia \\ ${ }^{4}$ Academic Technology Center, Bentley \\ College, Waltham, Mass
}

Conflicts of interest: None reported

\section{CORRESPONDING AUTHOR}

Amy K. Rosen, PhD, Senior Research Scientist

Center for Health Quality, Outcomes and Economic Research

Bedford VAMC (152)

200 Springs Road, Bedford MA 01730

akrosen@bu.edu.

\begin{abstract}
Outcome-based performance measurement and prospective payment are common features of the current managed care environment. Increasingly, primary care clinicians and health care organizations are being asked to assume financial risk for enrolled patients based on negotiated capitation rates. Therefore, the need for methods to account for differences in risk among patients enrolled in primary care organizations has become critical.
\end{abstract}

Although current risk-adjustment measures represent significant advances in the measurement of morbidity in primary care populations, they may not adequately capture all the dimensions of patient risk relevant to primary care. We propose a risk-adjustment framework for primary care that incorporates clinical features related to patients' health status and nonclinical factors related to patients' health behaviors, psychosocial factors, and social environment.

Without this broad perspective, clinicians with more unhealthy and more challenging populations are at risk of being inadequately compensated and inequitably compared with peers. The risk-adjustment framework should also be of use to health care organizations that have been mandated to deliver high-quality primary care but are lacking the necessary tools.

Ann Fam Med 2003;1:44-51. DOI: 10.1370/afm.6

\section{INTRODUCTION}

T he need for tools to assess the delivery of primary care services is becoming critical as efforts to contain health care costs and concerns about the quality of care increase. While the growth of managed care has strengthened the role of the primary care clinician, clinicians and primary care organizations are increasingly assuming financial risk for patients who are enrolled based on a negotiated per capita payment. ${ }^{1-3}$ Application of risk-adjustment methodologies is particularly relevant to primary care. Because morbidity is not distributed randomly in the population, ${ }^{4}$ adequate risk-adjustment methods are needed to eliminate the underlying differences in case-mix among physician practices. Unless comparisons across clinicians account for the predisposing characteristics of their primary care panels, primary care clinicians with patients that require more care may be at a serious economic disadvantage. Moreover, outcome-based assessments of quality of care are likely to be misleading.

The Institute of Medicine defines primary care as "the provision of integrated, accessible health care services by clinicians that are accountable for addressing a large majority of personal health care needs, developing a sustained partnership with patients, and practicing in the context of family and community." ${ }^{15}$ Central elements of primary care are first contact, continuity, comprehensiveness and coordination of care, and operating within the con- 
text of the family and community., ${ }^{4,6}$ Patients of primary care clinicians typically present for care of multiple problems that are often nonspecific and undifferentiated, span long time periods, and require a breadth of services, including prevention, mental health, and family care. ${ }^{4,7,9}$ Because these patients' needs range from minor complaints to complex complaints and multiple illnesses, it is necessary to obtain clinical and other patientspecific data to accurately predict outcomes or to identify high-risk patients for effective disease/case management programs. ${ }^{10}$

A variety of measures are currently applied to adjust for risk across primary care populations. ${ }^{11-14}$ Although these applications represent significant advances in the measurement of morbidity in primary care populations, they may not adequately capture every dimension of patient risk relevant to primary care. Current risk-adjustment measures emphasize the health status components of risk (eg, recorded diagnoses, demographic variables, pharmacy data), however, they do not capture nonclinical risk factors, such as patients' social and cultural circumstances, which are potentially important predictors of the use of health services. ${ }^{15}$ The current measures also focus primarily on cost and care utilization, so their ability to predict health outcomes, which is of particular interest in primary care, is poorly tested. ${ }^{16}$

Risk-adjustment measures that apply to primary care should therefore pay close attention to the key dimensions of primary care, incorporate the needs, characteristics, and health behaviors of individuals enrolled in primary care organizations, and be sensitive to the variety of clinical problems, outcomes, and interventions presented in primary care. In this article, we propose a risk-adjustment framework for primary care that includes both the health status components of risk as well as other factors that emphasize the multiple determinants of outcomes in primary care. Next, we describe current approaches to risk adjustment and evaluate the comprehensiveness of risk-adjustment measures for primary care. Finally, we discuss the addition of new factors for improving the suitability of current risk-adjustment measures for primary care in an effort to protect primary care clinicians from the risk of inadequate compensation and inaccurate performance measurement.

\section{RISK-ADJUSTMENT FRAMEWORK FOR PRIMARY CARE}

Primary care focuses on the patient and the population as units of analysis. A patient-centered approach focuses on 2 elements of primary care: (1) first contact and (2) comprehensiveness, because it accounts for all the care sought by an individual, independent of diag- nosis, over extended periods of time and across multiple encounters, clinicians, and settings. A patient-centered approach also reflects the longitudinal nature of primary care, where relationships between patients and clinicians often extend across episodes of care. ${ }^{4,5} \mathrm{~A}$ patient-centered approach addresses other important elements of primary care, because primary care begins at first contact and integrates all the treatments, services, and specialty referrals delivered across the continuum of patient care. Similarly, a population health perspective (eg, community-oriented primary care) reflects many of these elements. However, this perspective may involve a different set of risk adjusters. For example, mortality rates may be used to adjust the risk of the likelihood of future outcomes at the population level but not at the individual level.

The outcomes of interest in primary care reflect the breadth of primary care (ie, the wide range of services delivered, the diverse health conditions with which patients present, and the focus on integrating care across multiple problems). Resource-based outcomes focus on ambulatory visits, specialist referrals, and clinical preventive services. Clinical outcomes also are varied and include resolution of symptoms, frequency of preventable events, and changes in functional status, well-being, and other domains of health-related quality of life. ${ }^{4}$

The focus on longer timeframes and a broader set of health outcomes in primary care necessitates an expanded definition of "risk" than what is commonly applied in other settings, such as acute hospital care. This broader framework considers not only traditional inputs, such as demographic and clinical factors, but also nonclinical factors, such as healthrelated behaviors, psychosocial factors, and characteristics of the patients' social environment. Inclusion of these nonclinical factors implicitly recognizes the critical interplay between different health problems, actions of patients and clinicians, and environmental attributes in maintaining and enhancing health. ${ }^{17}$

Based on this broad framework, the dimensions of risk in primary care can be classified into 3 categories: (1) health status, (2) patient health-related behaviors and psychosocial factors, and (3) characteristics of the social environment. Although these distinctions are made for the purpose of analysis, it is important to recognize that they are inextricably linked in complex and multidirectional ways (Figure 1).

\section{DIMENSIONS OF RISK IN PRIMARY CARE}

\section{Health Status}

Health status is the most commonly applied dimension of risk and is measured using the following types of 


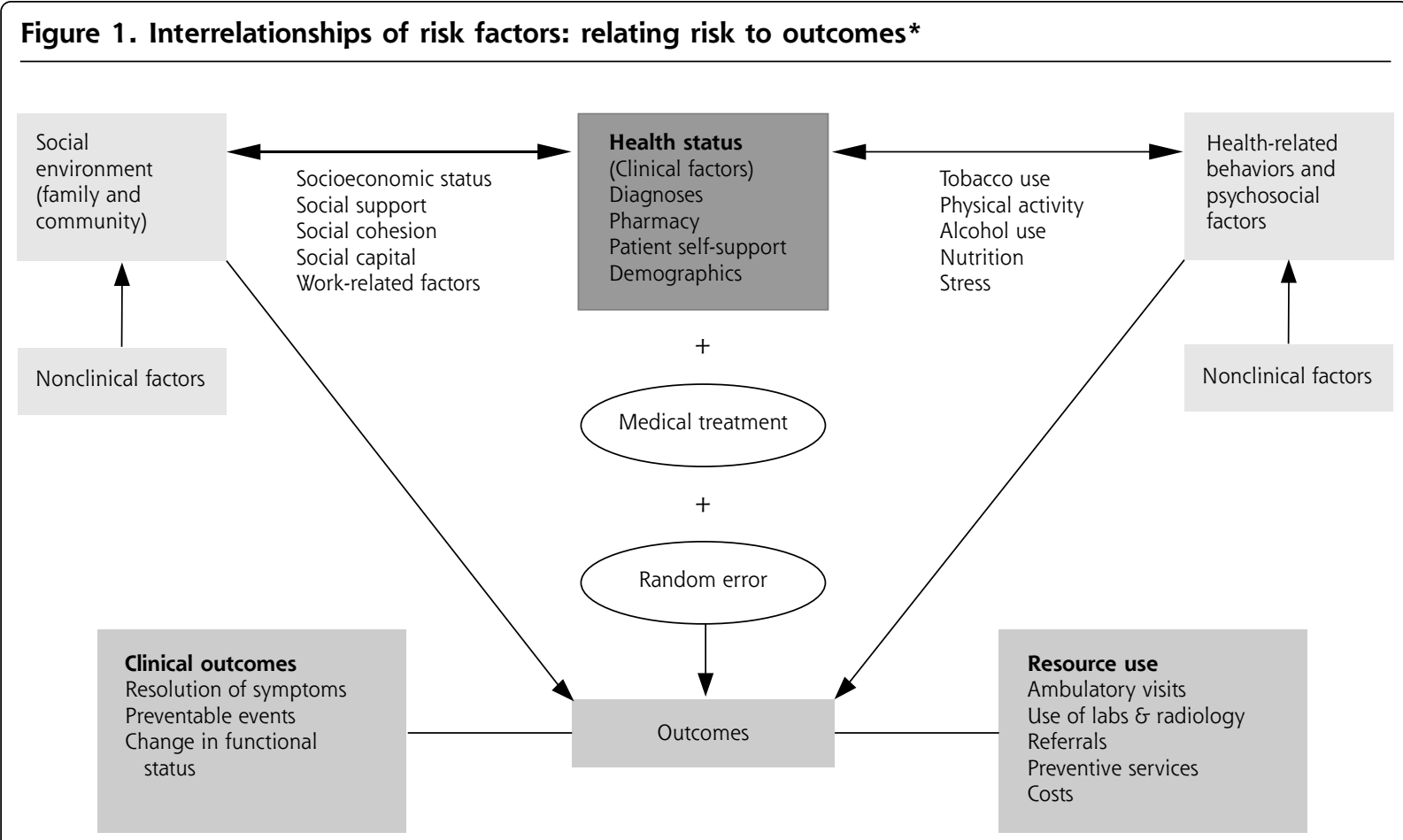

* Diagnosis-based measures are based on diagnoses, demographics and resource-use outcomes. Patient self-reported approaches are based on patient self-reported information (eg, health-related quality of life) and clinical outcomes.

inputs: (1) diagnoses assigned to patients by health care providers (diagnosis-based approaches) $i(2)$ types of medications taken by patients (pharmacy-based approaches) ${ }_{i}(3)$ patient self-reported health status measures (patient self-reported approaches); and (4) age, gender, and race/ethnicity (demographic approaches). Table 1 presents examples of the leading risk-adjustment measures for these various dimensions of risk.

Diagnosis-Based Approaches. Diseases and diagnoses are the principal ways in which illnesses are classified and quantified, and are vital in determining how clinicians organize health care. Diagnoses suggest appropriate investigations and interventions, imply the types of providers and care settings required, and help define follow-up strategies. Diagnosis-based, riskadjustment measures are valuable in categorizing clinical differences in resource consumption among individuals and subgroups, and possess several features that make them practical for primary care applications. Current measures are easy to implement, require limited data, and reasonably predict resource consumption. ${ }^{12,18}$ Through the use of additive models, diagnosis-based measures recognize the cumulative effect of multiple conditions in predicting total resource needs. This is an important factor for primary care. ${ }^{11}$
Several diagnosis-based, risk-adjustment measures have been developed and are described in detail in the health services literature. ${ }^{1-14,19-26}$ Although these measures were developed based on different populations and/or settings, they share similar approaches, structure, and origins. These computerized software systems use age, sex, and diagnoses generated from administrative claims/encounter data during a 1 -year time period to describe the medical problems of patients and their expected effect on health care resource consumption. ${ }^{11}$ These measures cluster diagnoses into clinically meaningful categories, which are then aggregated to provide a measure of health status that is used to predict future resource use. Based on the framework in Figure 1, dimensions of risk include diagnoses, demographics, and resource use outcomes.

Despite the intuitive appeal of the diagnosis-based approach, several problems occur when this approach is applied to primary care. First, patients commonly present with multiple symptoms and problems that may persist over time. Many of these problems never result in a definitive diagnosis and, consequently, are not included in diagnosis-based, risk-adjustment systems. When a diagnosis is made, many are "rule-out" diagnoses that may lead to potentially biased risk estimates. Second, diseases by themselves are inadequate 


\begin{tabular}{|c|c|c|c|c|}
\hline Measure & Primary Purpose & Inputs & Outputs & Data Sources \\
\hline $\begin{array}{l}\text { Diagnosis-based } \\
\text { ACGs, DCGs, CDPS }\end{array}$ & $\begin{array}{l}\text { Health-based payment; provider } \\
\text { profiling; quality assessment; } \\
\text { resource allocation; } \\
\text { disease/case management }\end{array}$ & $\begin{array}{l}\text { All diagnoses } \\
\text { from } 1 \text { year of } \\
\text { age; age; gender }\end{array}$ & $\begin{array}{l}\text { Number of ambulatory } \\
\text { visits per year; total } \\
\text { expenditures }\end{array}$ & $\begin{array}{l}\text { Medicare; Medicaid; } \\
\text { commercial populations } \\
\text { (HMO claims/encounter data) }\end{array}$ \\
\hline $\begin{array}{l}\text { Pharmacy-based } \\
\text { RxRisk }\end{array}$ & $\begin{array}{l}\text { Health-based payment; } \\
\text { disease/case management }\end{array}$ & $\begin{array}{l}\text { NDC codes; age; } \\
\text { gender }\end{array}$ & $\begin{array}{l}\text { Pharmacy costs; total } \\
\text { costs; ambulatory visits }\end{array}$ & $\begin{array}{l}\text { Commercial populations; } \\
\text { Medicaid data }\end{array}$ \\
\hline $\begin{array}{l}\text { Patient self-reported } \\
\text { SF-36 measures }\end{array}$ & Describe morbidity & Clinical data & $\begin{array}{l}\text { Ambulatory visits; total } \\
\text { expenditures; functional } \\
\text { status }\end{array}$ & Surveys; medical records \\
\hline
\end{tabular}

ACGs: Adjusted Clinical Groups. DCGs: Diagnostic Cost Groups. CDPS: Chronic Illness and Disability Payment System. HMO: Health Maintenance Organization. NDC: National Drug Codes. SF-36: Short Form Health Survey.

reflections of overall health status; information on disease severity is limited and only incorporates the physician's perspective. ${ }^{4}$

Third, accounting for comorbidities is particularly critical in primary care, especially when examining patterns of illness over extended periods of time. Diagnosis-based measures, such as Adjusted Clinical Groups, recognize the cumulative effect of "combinations of types of disorders ${ }^{\prime \prime} 19$; however, these broad clinical groupings do not fully account for interactions among types of comorbidities (eg, physical and psychiatric morbidities) or for the fact that individual comorbidities may be linked in a causal chain. For some outcomes, interactions among comorbidities may be more important than the occurrence of any specific morbidity. ${ }^{19,20}$ Thus, the existence or likelihood of occurrence of a specific disease or combination of diseases is an "incomplete approach" to measuring health status. ${ }^{4}$

Pharmacy-Based Approaches. The medications taken by patients are increasingly being used as proxies for health status. RxRisk, ${ }^{27}$ formerly the Chronic Disease Score, is a pharmacy measure that has been validated in numerous patient populations. ${ }^{28-31}$ Pharmacy-based risk-adjustment measures are attractive because computerized pharmacy data are generally available in a timely manner, provide insights about disease severity, and are often more complete and of higher quality than diagnostic information. ${ }^{28,29,32}$ This approach also appears to predict an individual's total health care cost as accurately as diagnoses. ${ }^{28}$ Pharmacy data may function better as a complement to diagnosis-based approaches rather than as a separate riskadjustment measure. Data are limited in capturing only the health status of individuals who receive pharmaceutical care. In addition, physicians may change their prescribing patterns if they discover that prescribing a particular drug will result in a large increase in payments to a health plan. Because pharmaceutical profiles have the potential to reflect a clinician's practice patterns more than an individual's health status, their use for risk adjustment in primary care should be monitored carefully. ${ }^{29}$

Patient Self-Reported Approaches. Patient selfreported approaches directly measure attributes of health status and are used alone or in combination with diagnosis-based measures. ${ }^{33-37}$ Patient approaches categorize individuals according to their self-perceived functional and physical health status, they deal implicitly with the impact of severity of illness and comorbidity, and they capture both positive (eg, vitality) and negative (eg, disability) aspects of health. Based on our framework (Figure 1), these approaches include patient self-reported information (eg, health-related quality of life and functional status) as dimensions of risk, and then link these dimensions to clinical outcomes.

Generic health-related quality of life (HRQOL) measures examine a breadth of domains: physical, social, and emotional functioning. This is particularly applicable to primary care where emphasis is on the "whole individual" and the presence of multiple health conditions rather than on the particular problem of a patient. ${ }^{4}$ Although generic health measures provide an accurate description of an individual's perceived health and functioning, ${ }^{38,39}$ some research suggests that they may be insensitive in capturing disease-specific information on HRQOL issues. ${ }^{40}$ This is important in primary care because diseases vary in their severity, manifestations, and impact. ${ }^{4,41}$ Generic health measures also lack the ability to account for individuals' preferences for different health states. Therefore, disease-specific measures, generic health status measures, and additional items that measure individual preferences would be useful in obtaining patient self-reported information.

However, there are certain caveats in applying HRQOL measures to assess the health status of primary care populations. First, a patient's health status does not necessarily equate with their "need" for health services. Second, specific domains of HRQOL may not apply to both children and adults seen in primary care. Third, most HRQOL instruments produce health 
ratings across several independent domains. The lack of a single comprehensive index makes long-term and population-based comparisons difficult. ${ }^{42}$ Fourth, despite the benefits of using detailed clinical information from patients, obtaining patient self-reported information from interviews or surveys is time-consuming, costly, and subject to methodologic flaws. ${ }^{43}$ Finally, no standardized method for collecting patient selfreported information exists, and many patient selfreported measures are available. ${ }^{44-48}$

Demographic Approaches. Demographic factors (age, sex, and race/ethnicity) are often used alone or in conjunction with diagnosis-based and pharmacy-based measures. When used alone, these variables represent proxies for health status. For example, elderly patients generally have more health problems and functional impairments than younger patients and are often at increased risk of poor outcomes. Because demographic variables account for a small percentage of the variation in outcomes, they are generally considered inadequate markers of health status by themselves. ${ }^{11,20,49,50}$ However, demographic variables are natural additions to risk-adjustment models in primary care, because practice populations often reflect a wide range of ages and gender, and racial/ethnic diversity. Clinical outcomes are known to vary among demographic subgroups. ${ }^{51}$ One caveat in using any of these demographic variables in risk-adjustment models is that they may obscure other important factors (eg, access to care, inequities in health care delivery, discrimination) that also may affect outcomes in primary care.

\section{Patient Behaviors and Psychosocial Factors}

Currently, no commercially marketed risk-adjustment systems that incorporate patient behaviors or psychosocial factors into their models are available, even though the link between health-related behaviors and health outcomes is well established. Behaviors such as tobacco use, physical inactivity, high-fat diets, and alcohol consumption increase the risk for both unfavorable clinical outcomes and high resource use. Similarly, psychosocial factors (eg, stress, individual coping behaviors) also can influence health outcomes and resource use. ${ }^{52}$

Inclusion of behavioral and psychosocial factors in risk adjustment recognizes the major role that clinicians play in changing patient behaviors and the importance of patient decisions and patient attitudes in health outcomes. Comprehensiveness in primary care mandates that primary care clinicians respond to a variety of health problems and also deliver a range of primary prevention services. Many preventive services are oriented to changing risky health behaviors before the onset of illness (eg, smoking cessation and nutri- tion counseling). ${ }^{53}$ However, patients' adherence to the care recommendations of their physicians and how well they cope with change, may influence the effectiveness of these interventions. Similarly, a patient's propensity to seek care can significantly confound analysis of clinical and resource-based outcomes. ${ }^{54}$

Accounting for health-related behaviors at baseline is complicated by concerns about the reliability of patient self-reported data and the ways in which behaviors and health interact. For example, the association between behavior and poor clinical outcomes is direct for some behaviors (eg, tobacco use), indirect for others (eg, physical activity), and more complex for yet others (eg, alcohol is protective of atherosclerotic heart disease at low doses but causes cardiomyopathy at higher ones). ${ }^{55}$ Another potential challenge related to the longitudinal nature of primary care is accounting for changes in health-related behaviors over time or for antecedent behaviors that precede the development of disease (eg, onset of smoking at an early age).

\section{Social Environment Factors}

There is increasing recognition that health outcomes are a product of individual factors (eg, biology, behavior, receipt of medical care) and of broader contextual factors relating to the social environment. ${ }^{17} \mathrm{~A}$ recent review identified 4 sets of social factors that are relevant for primary care: socioeconomic status, family and community social networks, social cohesion and social capital, and work-related factors. ${ }^{55}$ Most importantly, the health effects associated with social variables are often great and unambiguous, particularly as they relate to long-term outcomes. The Whitehall study of long-term mortality in male British civil servants found more than a threefold social class gradient between manual workers and their administrative counterparts. ${ }^{56}$ Socioeconomic status also is strongly related to chronic disease, poorer self-perceived health status, and decreased functioning. ${ }^{56-58}$ Although many social effects interact with health status and behaviors ${ }^{55}$ conventional risk factors cannot by themselves fully explain the effects. ${ }^{59}$ For instance, the inverse association between low socioeconomic status and excess mortality remains even after making adjustments for individual health-related behaviors. ${ }^{60}$ Because social conditions are not randomly distributed, failure to recognize environmental factors can lead to significant confounding.

Social factors are relevant to the patient-centered perspective of primary care because they are "generic" risks that cut across most health problems and conditions. Social risks unfold over time, consistent with the longitudinal nature of primary care. Measuring social risk at both the community (ie, population) and indi- 
vidual levels is necessary to obtain useful information relevant to each level. Socioeconomic status is the social factor that is included most often in risk-adjustment models because of its pervasive effects on the health of individuals and populations.

In the context of families and communities, factors such as social support, cohesion, and social capital (eg, community resources, obligations, networks) have an impact on health outcomes. For instance, among elderly persons, social support and networks are associated with reduced disability, improved recovery, and psychologic well-being. ${ }^{61,62}$ The inclusion of workplace, home, and community variables in risk-adjustment measures acknowledges that the preventive, diagnostic, and management strategies of primary care are optimally applied in the context of family and community. More than any other area of clinical medicine, primary care is charged with mitigating the health hazards that come with social disadvantage. However, the use of social factors in risk adjustment is complicated by the need to link timely community and family data with information about individuals. Another limiting factor is the lack of agreement on the methods for measuring social risk factors. ${ }^{63}$

\section{DISCUSSION}

Risk-adjustment measures are assuming an increasingly important role in the delivery and management of primary care. Without sensitive risk-adjustment measures that account for the breadth of primary care, primary care clinicians who care for sicker patients and more challenging populations risk being unfairly compensated and/or inaccurately judged on their performance. A broad risk-adjustment framework in primary care, as outlined in this paper, is critical to accommodate the range of patients seen, the multiple determinants of health, and the social context in which persons live. This perspective includes both clinical features related to patients' health status and nonclinical factors related to health behavior, psychosocial factors, and social circumstances.

Current risk-adjustment measures are frequently used for performance monitoring, health-based payments, and other applications; our discussion highlights the limitations of these measures for primary care. Because of the emphasis on health status by existing risk-adjustment measures, other dimensions of risk relevant to primary care (patient health-related behaviors, psychosocial factors, and social environment factors) are notably downplayed. As a result, comparisons of primary care clinicians rarely adjust for nonclinical risk factors, leaving a large proportion of the variance in outcomes unexplained. Further, risk-adjusted com- parisons may lead to a redistribution of resources between health care providers. Some clinicians will be financially rewarded and others will be penalized, particularly clinicians who are more vulnerable to losses from unpredictable risk.

Current risk-adjustment measures have other disadvantages that reduce their applicability to primary care. Diagnosis-based measures do not always account for the diversity of symptoms and conditions, comorbidity interactions, and progression of disease seen in primary care. Pharmacy-based measures are excellent proxies of disease, but they are prone to problems similar to those of diagnosis-based measures. Patient selfreported approaches are appealing because they reflect the patient-centered perspective of primary care, but they are limited because they primarily capture clinical risk adjusters.

While comparisons of outcomes across primary care clinicians should recognize and adjust for nonclinical risk factors, there are definite challenges to quantifying these variables. The current challenges are to collect an expanded set of variables and to link a variety of data sources, including administrative, survey, and community-level data. We suggest that, when possible, risk-adjustment measures include social factors, measured at the individual and the community levels. For example, marital status and indicators of socioeconomic status (eg, income and education) are readily available from administrative databases and can easily be incorporated into risk-adjustment models. A formidable task for future research is to develop practical methods that operationalize and combine nonclinical factors with health status variables. This should occur in conjunction with attempts to improve existing riskadjustment measures.

In conclusion, the implementation of a broad framework for risk adjustment in primary care is central to achieving high-quality care. With the growing importance of the primary care clinician in the managed care environment, the challenges faced in implementing a broad risk-adjustment framework should be outweighed by incentives to protect clinicians from inadequate compensation and inequitable comparisons with their peers.

To read commentaries or to post a response to this article, see the online version at http://www.annfammed.org/cgi/content/full/1/1/44.

Key words: Primary Care, Risk Adjustment, Managed Care, Case-mix Provider Profiling

Received October 21, 2002; Accepted January 28, 2003.

Versions of this manuscript were presented at the "Advancing the Methods in Practice-based Research Networks" Conference, American Academy of Family Physicians, Nov 29-30, 2001, San Antonio, Tex. 


\section{Funding support}

This research was partially supported by VA HSR\&D Service, Grant No. IIR 20-035-2, the Michael Smith Foundation for Health Research, and the Canadian Health Services Research Foundation.

\section{Acknowledgements}

The authors would like to thank Priti Trivedi, MHA, for assistance with manuscript preparation.

The views expressed are solely those of the authors.

\section{References}

1. Fowles J, Weiner JP, Knutson D, Fowler E, Tucker AM. Taking health status into account when setting capitation rates: a comparison of risk adjustment methods. JAMA 1996;276:1316-1321.

2. Hurley J, Hutchison B, Giacomini M, Birch S, Dorland J, Reid R, et al. Policy considerations in implementing capitation for integrated health systems. Ottawa, ON: Canadian Health Services Research Foundation; 1999

3. Vanselow NA. Better care and better outcomes: the continuing challenge. JAMA 1998;279:1392-1395.

4. Starfield B. Primary care: balancing health needs, services, and technology. New York, NY: Oxford University Press; 1998.

5. Institute of Medicine (US). Committee on the Future of Primary Care: America's Health in a New Era. Washington, DC: National Academy Press; 1996.

6. Grumbach K, Selby JV, Damberg C, et al. Resolving the gatekeeper conundrum: what patients value in primary care and referrals to specialists. JAMA 1999;282:261-266.

7. Safran DG, Taira DA, Rogers WH, Kosinski M, Ware JE, Tarlov AR. Linking primary care performance to outcomes of care. J Fam Pract 1998;47:213-220.

8. Fry J, Light D, Rodnick J, Orton P. Reviving primary care: a US-UK comparison. New York, NY: Radcliff Medical Press;1995:23-37.

9. Stange KC. The paradox of the parts and the whole in understanding and improving general practice. Int J Qual Health Care 2002;14:267268.

10. Ash A, Zhao Y, Ellis RP, Kramer MS. Finding future high-cost cases: comparing prior cost versus diagnosis-based methods. Health Serv Res 2001;36:194-206.

11. Ash AS, Ellis RP, Pope GC, et al. Using diagnoses to describe populations and predict costs. Health Care Financ Rev 2000;21:7-28.

12. Ellis RP, Pope GC, lezzoni LI, et al. Diagnosis-based risk adjustment for Medicare capitation payments. Health Care Financ Rev 1996;17:101-128

13. Kronick R, Gilmer T, Dreyfus T, Lee L. Improving health-based payment for Medicaid beneficiaries: CDPS. Health Care Financ Rev 2000;21:29-64.

14. Goldfield N, Averill R, Eisenhandler J. Payment and provider profiling of episodes of illness of clinical illnesses involving rehabilitation. J Outcome Meas 2000-2001;4:706-720.

15. Majeed A, Bindman AB, Weiner JP. A use of risk adjustment in setting budgets and measuring performance in primary care II: advantages, and practicalities. BMJ 2001;323:607-610.

16. McCall N, Krob J. Risk adjustment for dually eligible beneficiaries using long term care. Health Care Financ Rev 1998;20:71-90.

17. Evans RG, Stoddart GL. Producing health, consuming health care. Soc Sci Med 1990;31:1347-1363.
18. Weiner JP, Dobson A, Maxwell SL, Coleman K, Starfield BH. Riskadjusted Medicare capitation rates using ambulatory and inpatient diagnoses. Health Care Financ Rev 1996;17:77-99.

19. Starfield B, Weiner J, Mumford L, Steinwachs D. Ambulatory care groups: a categorization of diagnoses for research and management. Health Serv Res 1991;26:53-74

20. Weiner JP, Starfield B, Steinwachs D, Mumford LM. Development and application of a population-oriented measure of ambulatory care case-mix. Med Care 1991;29:452-72.

21. Ellis RP, Ash A. Refinements to the diagnostic cost group (DCG) model. Inquiry 1995;32:418-429.

22. Weiner JP, Starfield B, Lieberman R. The John Hopkins Ambulatory Care Groups (ACGs) - a case-mix system for UR, QA and capitation adjustment. HMO Pract 1992;6:13-19.

23. Weiner JP, Starfield BH, Powe NR, Stuart ME, Steinwachs DM. Ambulatory care practice variation within a Medicaid program. Health Serv Res 1996;30:751-770.

24. Weiner JP, Tucker AM, Collins AM, et al. The development of a riskadjusted capitation payment system: the Maryland Medicaid Model. J Ambul Care Manage 1998;21:29-52.

25. Kronick R, Dreyfus T, Lee L, Zhou Z. Diagnostic risk adjustment for Medicaid: the disability payment system. Health Care Financ Rev $1996 ; 17: 7-33$

26. Goldfield N, Averill R, Eisenhandler J, et al. The prospective risk adjustment system. J Ambul Care Manage 1999;22:41-52.

27. Clark DO, Korff NV, Saunders K, Baluch WM, Simon GE. A chronic disease score with empirically derived weights. Med Care 1995;33:783-795

28. Fishman PA, Shay DK. Development and estimation of a pediatric chronic disease score using automated pharmacy data. Med Care 1999;37:874-883

29. Gilmer T, Kronick R, Fishman P, Ganiats TG. The Medicaid Rx Model: Pharmacy-based risk adjustment for public programs. Med Care 2001;39:1188-1202.

30. Lamers LM, van Vliet RC. Multiyear diagnostic information from prior hospitalization as a risk-adjuster for capitation payments. Med Care 1996;34:549-561.

31. Roblin DW. Physician profiling using outpatient pharmacy data as a source for case mix measurement and risk adjustment. J Ambul Care Manage 1998;21:68-84.

32. Welch P. Outpatient encounter data for risk adjustment: strategic issues for Medicare and Medicaid. J Ambul Care Manage 2002;25:1-15.

33. Hornbrook MC, Goodman MJ. Assessing relative health plan risk with the RAND-36 health survey. Inquiry 1995;32:56-74.

34. Hornbrook MC, Goodman MJ. Chronic disease, functional health status, and demographics: a multi-dimensional approach to risk adjustment. Health Serv Res 1996;31:283-307.

35. Lamers LM. Risk-adjusted capitation based on the Diagnostic Cost Group Model: an empirical evaluation with health survey information. Health Serv Res 1999;33:1727-1744.

36. Pope GC, Adamache KW, Walsh EG, Khandker RK. Evaluating alternative risk adjusters for Medicare. Health Care Fin Rev 1998;20:109129.

37. Zhao Y, Ellis RP, Ash AS, et al. Measuring population health risks using inpatient diagnoses and outpatient pharmacy data. Health Serv Res 2001;36:180-193.

38. Bierman AS, Lawrence WF, Haffer SC, Clancy CM. Functional health outcomes as a measure of health care quality for Medicare beneficiaries. Health Serv Res 2001;36:90-109.

39. Lawrence WF, Fryback DG, Martin PA, Klein BE, Klein R. Health status and hypertension: a population-based study. J Clin Epidemiol 1996:49:1239-1245. 
40. Guyatt GH, Naylor D, Juniper E, Heyland DK, Jaeschke R, Cook DJ. Users' guides to the medical literature. XII. How to use articles about health-related quality of life. Evidence-Based Medicine Working Group. JAMA 1997;277:1232-1237.

41. Stein RE, Jessop DJ. A noncategorical approach to chronic childhood illness. Public Health Rep 1982;97:354-362.

42. McHorney CA, Cohen AS. Equating health status measures with item response theory: illustrations with functional status items. Med Care 2000;38:1143-59.

43. Physician Payment Review Commission. Annual report to Congress Washington, DC: US Government Printing Office; 1994.

44. Bergner M, Bobbitt RA, Carter WB, Gilson BS. The Sickness Impact Profile: development and final revision of a health status measure. Med Care 1981;19:787-805.

45. Bergner M, Bobbitt RA, Kressel S, Pollard WE, Gilson BS, Morris JR. The Sickness Impact Profile: conceptual formulation and methodology for the development of a health status measure. Int J Health Serv 1976;6:393-415.

46. EuroQol Group. EuroQol-a new facility for the measurement of health-related quality of life. Health Policy 1990;16:199-208.

47. Kaplan RM, Anderson JP. The quality of well-being scale: rationale for a single quality of life index. In: Walker SR, Rosser, RM, eds. Quality of life: assessment and application. Lancaster, Mass: MIT Press; 1998.

48. Hunt SM, McEwen J. The Nottingham Health Profile: subjective health status and medical consultations. Soc Sci Med [A] 1980;15 (3 Pt 1):221-229.

49. Reid RJ, MacWilliam L, Verhulst L, Roos N, Atkinson M. Performance of the ACG case-mix system in two Canadian provinces. Med Care 2001;36:86-99.

50. Rosen AK, Loveland SM, Anderson JJ, et al. Evaluating diagnosisbased case-mix measures: how well do they apply to the VA population? Med Care 2001;39:692-704.
51. Williams DR. Race/ethnicity and socioeconomic status; measurement and methodological issues. Int J Health Serv 1996;26:483-505.

52. Baum A, Posluszny DM. Health psychology: mapping biobehavioral contributions to health and illness. Annu Rev Psychol 1999;50:137-163.

53. US Preventative Task Force. Guide to clinical preventative services. 2nd ed. Baltimore, Md: Williams \& Wilkins; 1996.

54. Ramsay LE. The hypertension detection and follow-up program: 17 years on. JAMA 1997;277:167-170.

55. Institute of Medicine (US). The interplay of biological, behavioral, and societal influences. Washington, DC: National Academy Press; 2001.

56. Marmot MG, Davey G, Smith S, et al. Health inequalities among British civil servants: the Whitehall II study. Lancet 1991;337:1387-1393.

57. Kaplan GA, Keil JE. Socioeconomic factors and cardiovascular disease: a review of the literature. Circulation 1993:88:1973-1998.

58. Breeze E, Fletcher AE, Leon DA, Marmot MG, Clarke RJ, Shipley MJ. Do socioeconomic disadvantages persist into old age? Self-reported morbidity in a 29-year follow-up of the Whitehall study. Am J Public Health 2001;91:277-283.

59. Hertzman C, Wiens M. Child development and long-term outcomes: a population health perspective and summary of successful interventions. Soc Sci Med 1996;43:1083-1095.

60. Haan M, Kaplan GA, Camacho T. Poverty and health. Prospective evidence from the Alameda County study. Am J Epidemiol 1987;125: 989-998.

61. Mendes de Leon CF, Glass TA, Beckett LA, Seeman TE, Evans DA, Berkman LF. Social networks and disability transitions across eight intervals of yearly data in the New Haven EPESE. J Gerontol B Psychol Sci Soc Sci 1999;54:S162-172.

62. Kawachi I, Berkman LF. Social ties and mental health. J Urban Health 2001;78:458-467

63. Kawachi I, Subramanian SV, Almeida-Filho N. A glossary for health inequalities. J Epidemiol Community Health 2002;56:647-652. 